\title{
BMJ Open Association between vitamin D receptor gene FokI polymorphism and skeletal fluorosis of the brick-tea type fluorosis: a cross sectional, case control study
}

\author{
Dan Yang, ${ }^{1,2,3}$ Yang Liu, ${ }^{1,2}$ Yanru Chu, ${ }^{1,2}$ Qing Yang, ${ }^{1,2}$ Wei Jiang, ${ }^{1,2}$ \\ Fuxun Chen, ${ }^{1,2}$ Dandan Li, ${ }^{1,2}$ Ming Qin, ${ }^{1,2}$ Dianjun Sun, ${ }^{1,2}$ Yanmei Yang, ${ }^{1,2}$ \\ Yanhui $\mathrm{Gao}^{1,2}$
}

To cite: Yang D, Liu Y, Chu Y, et al. Association between vitamin $D$ receptor gene Fokl polymorphism and skeletal fluorosis of the bricktea type fluorosis: a cross sectional, case control study. BMJ Open 2016;6:e011980. doi:10.1136/bmjopen-2016011980

- Prepublication history for this paper is available online. To view these files please visit the journal online (http://dx.doi.org/10.1136/ bmjopen-2016-011980)

DY and YL contributed equally.

Received 19 March 2016 Revised 11 October 2016 Accepted 18 October 2016

CrossMark

For numbered affiliations see end of article.

Correspondence to

Dr Y Gao;

gaoyh411@163.com and

Dr Y Yang;

yangym0916@163.com

\section{ABSTRACT}

Background: Brick-tea type fluorosis is a public health concern in the north west area of China. The vitamin $D$ receptor (VDR)-Fokl polymorphism is considered to be a regulator of bone metabolism and calcium resorption. However, the association of VDRFokl polymorphism with the risk of brick-tea type fluorosis has not been reported.

Materials and methods: A cross sectional, case control study was conducted in three provinces (Inner Mongolia, Qinghai and Sinkiang) in China. The fluoride content of Brick-tea water and urine was tested using the standards GB 1996-2005 and WS/T89-2006 (China), respectively. Skeletal fluorosis was diagnosed using the standard WS/192-2008 (China). The VDRFokl polymorphism was detected by the Sequenom MassARRAY system.

Result: Compared with carriers of the CC genotype, participants with the CT/TT genotype had a significantly decreased risk of skeletal fluorosis (OR=0.761 (95\% $\mathrm{Cl} 0.580$ to 0.997)), after adjustment for risk factors. When investigated among ethnic groups, the protective effect of the CT/TT genotype was limited in the Mongolian participants (OR=0.525 (95\% $\mathrm{Cl} 0.278$ to 0.991$)$ ). Moreover, the interaction of VDRFokl with risk factors was only found in Mongolian participants: the protective effect of the CT/TT genotype was limited to participants with $>7.0 \mathrm{mg} /$ day daily intake of tea fluoride $(\mathrm{OR}=0.085(95 \%$ $\mathrm{Cl} 0.009$ to 0.851 ), participants with $>3.2 \mathrm{mg} / \mathrm{L}$ urine fluoride (OR=0.103 (95\% $\mathrm{Cl} 0.017$ to 0.633$)$ ) or participants aged $46-65$ years $(O R=0.404(95 \%$ $\mathrm{Cl} 0.177$ to 0.922 ).

Conclusions: Our data suggest that the $\mathrm{CT} / \mathrm{TT}$ genotype of VDR-Fokl may be a protective factor for brick-tea type skeletal fluorosis, and this effect is pronounced in Mongolian participants.

\section{INTRODUCTION}

Fluorosis is caused by long term exposure to excessive amounts of fluoride. ${ }^{1}{ }^{2}$ Skeletal fluorosis is a serious clinical outcome of

\section{Strengths and limitations of this study}

- This study includes Tibetan, Kazakh, Mongolian and Han participants.

- Overall participants were older than 16 years, and were born and grew up in Inner Mongolia, Qinghai or Sinkiang province, People's Republic of China.

- This is the first report describing the association between Fokl polymorphism and skeletal fluorosis, overall and by ethnicity.

- A limitation is that the sample size of the Tibetan and Han participants was inadequate.

fluorosis, which causes pain and damage to bones and joints, and even crippling. ${ }^{3}$ Fluorosis affects millions of people around the world, and there are no established treatments for fluorosis patients. It has become a major public health issue around the world. ${ }^{4-6}$ According to the source of fluoride in the human body, fluorosis can be divided into three groups: drinking water type, burning coal type and brick-tea type. The brick-tea type of fluorosis is caused by habitual consumption of brick-tea in large quantities. ${ }^{7}$ In China, the prevalence and severity of both the water type and coal burning type of fluorosis has declined but the brick-tea type fluorosis is a severe public health issue because it is impossible to alter the habitual consumption of brick-tea.

Skeletal fluorosis is a chronic metabolic bone disease caused by excessive accumulation of fluoride in bones, and abnormal bone metabolism is the most prominent characteristic. Apart from the level and duration of fluoride exposure, the diversity of clinical manifestations of skeletal fluorosis correlates directly with the complexity of bone metabolism. ${ }^{8}$ Bone metabolism is 
characterised by two opposite but finely coupled processes: bone formation and resorption. It is known that individual differences in abnormal bone metabolism in response to the disease largely depend on genetic susceptibility. ${ }^{9}$ A previous study reported that polymorphism of the myeloperoxidase gene ${ }^{10}$ is related to the burning coal type fluorosis, which suggests that gene polymorphism may play an important role in the pathogenesis of skeletal fluorosis.

Among the potential genes relevant to bone metabolism, ${ }^{9}$ the vitamin D receptor (VDR) gene is considered to be an important candidate. ${ }^{11}$ The VDR gene, located on chromosome 12 (12q12-14), plays an important role in bone metabolism, including intestinal calcium absorption. $^{12}{ }^{13}$ It is reported that fluoride modulates VDR mRNA expression. ${ }^{14}$ Since Morrison first reported that VDR gene polymorphism is associated with bone mineral density and that it can predict bone density, ${ }^{15}$ several VDR gene restriction endonuclease sites, such as FokI (rs2228570), BsmI (rs1544410), ApaI (rs7975232) and TaqI (rs731236), have been used in population based studies. ${ }^{13} 1516$ Different VDR gene polymorphism plays different roles in regulating bone metabolism. ${ }^{17-20}$ FokI polymorphism, a $\mathrm{C} \rightarrow \mathrm{T}$ transition found within the translation initiation site in exon 2, results in long and short variants of VDR by creating an upstream initiation codon (ACG $\rightarrow$ ATG). ${ }^{21}$ The FokI polymorphism is related to bone mineral density and calcium absorption. $^{21-23}$ Some reports suggest that the short receptor protein $(\mathrm{C}$ allele), initiated from the second ATG site, may play a more active role in VDR responsive gene expression because it interacts more efficiently with the transcriptional factor IIB compared with the long receptor protein (T allele), initiated from the first ATG site. ${ }^{24}$ The association between FokI polymorphism and bone mineral density has been reported ${ }^{21-23}$ but the association of the FokI polymorphism with the risk of skeletal fluorosis has not been reported.

Our previous study demonstrated ethnic differences in the prevalence of brick-tea type fluorosis and that the glutathione S-transferases rs1695 polymorphism may play an important role in the pathogenesis of brick-tea fluorosis. ${ }^{25}$ However, there are no studies on the effect of VDR-FokI on skeletal fluorosis of the brick-tea type. Therefore, in this study, we conducted a cross sectional, case control study in the brick-tea fluorosis area of China to investigate the association between the FokI polymorphism and skeletal fluorosis, overall or by ethnicity.

\section{MATERIALS AND METHODS}

\section{Subjects and data collection}

Using the brick-tea type fluorosis survey data, we undertook a cross sectional, case control study in 16 villages from the Inner Mongolia, Qinghai and Sinkiang provinces, People's Republic of China, from July to August 2012. In this study, participants were older than 16 years, and were born and grew up in their village. Each participant received a questionnaire survey and clinical examination. The clinical examination included physical examination, medical history and X-ray diagnosis (Beijing Longsafe Imaging Technology Co, Beijing City, China). The content of the questionnaire included general information on the respondent (name, sex, age, education, economic income, history of bone related disease, etc) and fluoride exposure (amount of brick-tea water drunk per day, consumption of brick-tea per year). In addition, we also collected blood, urine and brick-tea water samples.

\section{Diagnose of skeletal fluorosis}

Skeletal fluorosis was diagnosed according to the Chinese diagnostic criteria of endemic skeletal fluorosis (WS192-2008, China). As described in a previous report, ${ }^{25}$ the diagnose of skeletal fluorosis was based on X-ray findings, including osteoporosis, osteomalacia, sclerosis, ossification of soft tissue and joint degeneration in the forearm, shank and pelvic, and could be classified into three categories: mild, moderate or severe.

\section{Determination of fluoride concentration}

All urine and brick-tea water samples were stored at $-20^{\circ} \mathrm{C}$ until use. Urinary fluoride content was determined by the fluoride ion electrode method based on China's Urinary Fluoride Detection-Fluoride Electrode Method WS/T89-1996. The concentration of brick-tea water was also determined by the fluoride ion electrode method using the standard GB19965-2005 (China).

\section{Genotyping}

All blood samples were stored at $-80^{\circ}$ until use. Genomic DNA was extracted from blood samples using a DNA extraction kit (Axygen Biosciences, Union City, USA). DNA concentration was tested by TU1901 spectrophotometry (Purkinje General Company, Beijing City, China). When the DNA concentration was $>20 \mu \mathrm{g} / \mathrm{mL}$, the extracted DNA was preserved at $-80^{\circ} \mathrm{C}$. Genotyping sequencing from the extract was performed by the Shanghai Fenglin Clinical Laboratory Company (http:// www.fenglinlab.com/index.asp) using the Sequenom MassARRAY system (Sequenom, San Diego, California, USA). The primer sequence of the FokI: forward 5'-ACG TTG GAT GTG GCC TGC TTG CTG TTC TTA-3'; reverse 5'-ACG TTG GAT GAC GTT CCG GTC AAA GTC TCC-3'; extended 5'-GTG CTG GCC GCG ATT GCC TCC-3'. For genotyping sequencing quality control, blinded blood duplicates were used.

\section{Statistical analysis}

Most statistical analyses were conducted using SPSS V.19.0 (SPSS, Chicago, Illinois, USA). Post hoc power of the study was estimated using G*Power software (V.3.1). Pearson's $\chi^{2}$ test was used to test for differences between fluorosis patients and controls. ORs and corresponding 
95\% CIs were calculated for skeletal fluorosis risk using logistic regression. Testing for deviation from HardyWeinberg equilibrium was performed within participants stratified by cases and controls using the $\chi^{2}$ test. Wald's test statistic was used for test gene-environment interactions. The significance level was taken as $\mathrm{p}<0.05$.

\section{Ethics statement}

The study was proved by the Harbin Medical University Ethics Committee (HMUIRB20120021). All participants provided signed informed consent, and we also obtained written informed consent from the guardians of the minors. For the brick-tea water sample collections, no specific permits were required. The locations were not privately owned or protected in any way, and this field study did not involve endangered or protected species.

\section{RESULTS}

\section{Participant characteristics}

In total, 1284 subjects participated in this study. There were 336 subjects who were diagnosed with skeletal fluorosis with a prevalence of $26.2 \%(336 / 1284)$. The demographics of the skeletal fluorosis cases and controls are presented in table 1 . The skeletal fluorosis cases were significantly older than controls $(p<0.001)$, and there were more men in the skeletal fluorosis group compared with controls $(\mathrm{p}=0.015)$. The skeletal fluorosis cases were significantly more likely to have a greater

\begin{tabular}{|c|c|c|c|}
\hline & $\begin{array}{l}\text { Cases } \\
\text { (n (\%)) }\end{array}$ & $\begin{array}{l}\text { Controls } \\
\text { (n (\%)) }\end{array}$ & p Value \\
\hline Age (years) & & & $<0.001$ \\
\hline$\leq 45$ & 59 (17.6) & 331 (34.9) & \\
\hline $46-65$ & $203(60.4)$ & 499 (52.6) & \\
\hline$\geq 66$ & 74 (22.0) & $118(12.4)$ & \\
\hline Sex & & & 0.015 \\
\hline Male & $156(46.4)$ & 368 (38.8) & \\
\hline Female & $180(53.6)$ & $580(61.2)$ & \\
\hline Ethnicity & & & $<0.001$ \\
\hline Tibetan & $123(36.6)$ & 185 (19.5) & \\
\hline Kazakh & $98(29.2)$ & $192(20.3)$ & \\
\hline Mongolian & 58 (17.3) & $203(21.4)$ & \\
\hline Han & 57 (17.0) & 368 (38.8) & \\
\hline ITF (mg/day) & & & $<0.001$ \\
\hline$\leq 3.5$ & $91(27.1)$ & 309 (32.6) & \\
\hline $3.5-7.0$ & $131(39.0)$ & $446(47.0)$ & \\
\hline$>7.0$ & 114 (33.9) & $193(20.4)$ & \\
\hline UF (mg/L) & & & $<0.001$ \\
\hline$\leq 1.6$ & 107 (31.8) & $494(52.1)$ & \\
\hline $1.6-3.2$ & 119 (35.4) & $266(28.1)$ & \\
\hline$>3.2$ & $110(32.7)$ & 188 (19.8) & \\
\hline \multicolumn{4}{|c|}{$\begin{array}{l}\text { Percentages are adjusted for sampling weights and may not sum } \\
\text { to } 1 \text { due to rounding. } \\
\text { p value, difference by case status. } \\
\text { ITF, daily intake of tea fluoride; UF, urine fluoride. }\end{array}$} \\
\hline
\end{tabular}

daily intake of tea fluoride (ITF) $(\mathrm{p}<0.001)$ and a higher urine fluoride (UF) status $(\mathrm{p}<0.001)$. In addition, ethnic differences in skeletal fluorosis were observed $(\mathrm{p}<0.001)$ : most common in Tibetan cases followed by Kazakh cases, and least common in Mongolian and Han cases.

\section{Association of the VDR-Fokl polymorphism with skeletal fluorosis}

Testing for deviation from Hardy-Weinberg equilibrium was performed within the control group, stratified by ethnicity, using the $\chi^{2}$ test. All ethnic participants were found to be in Hardy-Weinberg equilibrium for VDR-FokI. In our study, the VDR-FokI polymorphism followed a dominant model of inheritance, so we divided participants into two groups based on the presence or absence of the $\mathrm{T}$ allele: $\mathrm{CC}$ and $\mathrm{CT} / \mathrm{TT}$ groups (table 2). Participants with the CT/TT genotype had a significantly decreased risk of skeletal fluorosis (OR=0.717 (95\% CI 0.556 to 0.925$)$ ). After adjustment for risk factors, the protective effect of the CT/TT genotype remained statistically significant $(\mathrm{OR}=0.761 \quad(95 \%$ CI 0.580 to 0.997$)$ ). In addition, there was the suggestion of a difference in skeletal fluorosis risk by ethnicity in relation to the VDR-FokI polymorphism. After adjustment for risk factors, the protective effect of the CT/TT genotype was limited in Mongolian participants $(\mathrm{OR}=0.525$ (95\% CI 0.278 to 0.991$))$. The smaller percentage of Mongolian participants in our analysis appeared to be driving the overall $>20 \%$ reduction in risk, as our data did not show a similar reduction in the other three ethnic groups.

Given the non-significant nature of the association of the VDR-FokI polymorphism in Tibetan, Kazakh and Han participants, it was necessary to determine if our study had adequate power to detect the true association if present in these populations. We estimated the power of our study using G Power software (V.3.1). We found power values of $98.9 \%$ and $99.4 \%$ at $\mathrm{p}=0.05$ for the participants overall and for Mongolian participants, respectively. The power values for the Tibetan, Kazakh and Han participants were $11.7 \%, 64.5 \%$ and $8.1 \%$, respectively. This indicates that our sample size for Tibetan and Han participants was inadequate, and the study was insufficiently powered to detect a true association of the VDR-FokI polymorphism with skeletal fluorosis, if it exists, in these ethnic participants.

\section{Stratification by potential risk factor}

We investigated the potential interactions between FokI-SNP and risk factor in Mongolian participants (table 3). For Mongolian participants, a decreased risk of skeletal fluorosis among carriers with the CT/TT genotype was limited to participants with $>7.0 \mathrm{mg} /$ day ITF $(\mathrm{OR}=0.085(95 \%$ CI 0.009 to 0.851$)$ vs $\mathrm{OR}=0.538$ (95\% CI 0.216 to 1.337 ) in participants with $\leq 3.5 \mathrm{mg} /$ day ITF, vs OR=0.671 (95\% CI 0.220 to 2.048$)$ in participants with $3.5-7.0 \mathrm{mg} /$ day ITF). We also observed that a 
Table 2 Risk of skeletal fluorosis associated with VDR-Fokl polymorphic genotypes in study participants overall and stratified by ethnicity

\begin{tabular}{|c|c|c|c|c|}
\hline Genotype & $\begin{array}{l}\text { Case } \\
(\mathrm{n}(\%))\end{array}$ & $\begin{array}{l}\text { Control } \\
\text { n (\%) }\end{array}$ & Crude OR (95\% Cl) & Adjusted OR $(95 \% \mathrm{CI})^{*}$ \\
\hline \multicolumn{5}{|c|}{ All participants } \\
\hline $\mathrm{CC}$ & $143(42.6)$ & $329(34.7)$ & $1.0(\mathrm{ref})$ & 1.0 (ref) \\
\hline $\mathrm{CT}+\mathrm{TT}$ & $193(57.4)$ & 619 (65.3) & 0.717 (0.556 to 0.925$)$ & 0.761 (0.580 to 0.997$)$ \\
\hline \multicolumn{5}{|l|}{ Tibetan } \\
\hline $\mathrm{CC}$ & $44(35.8)$ & $62(33.5)$ & 1.0 (ref) & $1.0(\mathrm{ref})$ \\
\hline $\mathrm{CT}+\mathrm{TT}$ & 79 (64.2) & $123(66.5)$ & 0.905 (0.561 to 1.461$)$ & 0.947 (0.562 to 1.598$)$ \\
\hline \multicolumn{5}{|l|}{ Kazakh } \\
\hline $\mathrm{CC}$ & $50(51.0)$ & $85(44.3)$ & 1.0 (ref) & $1.0($ ref) \\
\hline $\mathrm{CT}+\mathrm{TT}$ & $48(49.0)$ & 107 (55.7) & 0.763 (0.468 to 1.242$)$ & $0.729(0.439$ to 1.210$)$ \\
\hline \multicolumn{5}{|l|}{ Mongolian } \\
\hline CC & $31(53.4)$ & $70(34.5)$ & 1.0 (ref) & $1.0(\mathrm{ref})$ \\
\hline $\mathrm{CT}+\mathrm{TT}$ & 27 (46.6) & $133(65.5)$ & 0.458 (0.254 to 0.828$)$ & $0.525(0.278$ to 0.991$)$ \\
\hline \multicolumn{5}{|l|}{ Han } \\
\hline $\mathrm{CC}$ & $18(31.6)$ & $112(30.4)$ & $1.0(\mathrm{ref})$ & $1.0(\mathrm{ref})$ \\
\hline $\mathrm{CT}+\mathrm{TT}$ & $39(68.4)$ & $256(69.6)$ & $0.948(0.520$ to 1.729$)$ & $0.945(0.503$ to 1.774$)$ \\
\hline
\end{tabular}

Table 3 Association of VDR-Fokl polymorphic genotypes with skeletal fluorosis in Mongolian subjects, stratified by potential risk factor levels

\begin{tabular}{|c|c|c|c|c|c|}
\hline & \multicolumn{2}{|c|}{ Genotype CC } & \multicolumn{2}{|c|}{ Genotype CT+TT } & \multirow[b]{2}{*}{ OR $(95 \% \mathrm{Cl})$} \\
\hline & $\begin{array}{l}\text { Case } \\
\text { n (\%) }\end{array}$ & $\begin{array}{l}\text { Control } \\
\text { n (\%) }\end{array}$ & $\begin{array}{l}\text { Case } \\
\text { n (\%) }\end{array}$ & $\begin{array}{l}\text { Control } \\
\text { n (\%) }\end{array}$ & \\
\hline \multicolumn{6}{|c|}{ ITF (mg/day) } \\
\hline$\leq 3.5$ & $13(46.4)$ & $26(31.7)$ & $15(53.6)$ & $56(68.3)$ & $0.538(0.216$ to 1.337$) \dagger$ \\
\hline $3.5-7.0$ & $9(50.0)$ & $37(36.6)$ & $9(50.0)$ & 64 (63.4) & $0.671(0.220$ to 2.048$) \dagger$ \\
\hline$>7.0$ & $9(75.0)$ & $7(35.0)$ & $3(25.0)$ & $13(65.0)$ & $0.085(0.009$ to 0.851$) \dagger$ \\
\hline \multicolumn{6}{|l|}{ UF (mg/L) } \\
\hline$\leq 1.6$ & $10(40.0)$ & $36(29.3)$ & $15(60.0)$ & $87(70.7)$ & $0.617(0.245$ to 1.555$) \ddagger$ \\
\hline $1.6-3.2$ & $10(55.6)$ & $30(47.6)$ & $8(44.4)$ & $33(52.4)$ & $0.772(0.246$ to 2.426$) \ddagger$ \\
\hline$>3.2$ & $11(73.3)$ & $4(23.5)$ & $4(26.7)$ & $13(76.5)$ & $0.103(0.017$ to 0.633$) \ddagger$ \\
\hline \multicolumn{6}{|c|}{ Age (years) } \\
\hline$\leq 45$ & $6(42.9)$ & 27 (29.7) & $8(57.1)$ & $64(70.3)$ & $0.443(0.127$ to 1.548$) \S$ \\
\hline $46-65$ & $23(60.5)$ & $35(35.4)$ & 15 (39.5) & $64(64.6)$ & $0.404(0.177$ to 0.922$) \S$ \\
\hline$\geq 66$ & 2 (33.3) & $8(61.5)$ & $4(66.7)$ & $5(38.5)$ & $3.808(0.156$ to 93.179$) \S$ \\
\hline \multicolumn{6}{|c|}{$\begin{array}{l}\text { Bold indicates } p<0.05 \text {. } \\
\text { †Adjusted for age, sex and UF. } \\
\text { fAdjusted for age, sex and ITF. } \\
\text { \&Adjusted for sex, ITF and UF. } \\
\text { ITF, daily intake of tea fluoride; UF, urine fluoride; VDR, vitamin D receptor. }\end{array}$} \\
\hline
\end{tabular}

decrease in the risk of skeletal fluorosis among carriers with the CT/TT genotype was limited to participants with $>3.2 \mathrm{mg} / \mathrm{L}$ UF $(\mathrm{OR}=0.103$ (95\% CI 0.017 to 0.633 ) vs $\mathrm{OR}=0.617$ (95\% CI 0.245 to 1.555$)$ in participants with $\leq 1.6 \mathrm{mg} / \mathrm{L}$ UF, vs $\mathrm{OR}=0.772 \quad(95 \%$ CI 0.246 to 2.426) in participants with $1.6-3.2 \mathrm{mg} / \mathrm{L}$ UF). In addition, we also noticed that a decrease in the risk of skeletal fluorosis among carriers with the CT/TT genotype was limited to participants aged $46-65$ years $(\mathrm{OR}=0.404$ (95\% CI 0.177 to 0.922$)$ vs (OR=0.443 (95\% CI 0.127 to $1.548)$ in participants aged $\leq 45$ years vs $\mathrm{OR}=3.808(95 \%$ CI 0.156 to 93.179 ) in participants aged $\geq 66$ years).

\section{DISCUSSION}

Although high fluoride exposure is extremely relevant to skeletal fluorosis, it is not the only factor influencing susceptibility to fluorosis. Not everyone living in areas with naturally high fluoride levels in water suffers from fluorosis. ${ }^{56}$ Three inbred strains of mice (A/J, SWR/J and $129 \mathrm{P} 3 / \mathrm{J}$ ) that showed different susceptibilities to dental fluorosis displayed variations in bone response to fluoride exposure. ${ }^{27-29}$ Hence genetics may influence the bone response of individuals to fluoride exposure. In our previous study, we observed that the prevalence and severity in different ethnic participants were 
different, which suggested the possible contribution of a genetic differences in fluorosis disparities. ${ }^{25}$ In addition, distribution of environment factors related to fluoride exposure, including age, ITF and UF, differs by ethnicity. As a result, it is plausible that the interaction between gene and environmental factors may explain, in part, the racial/ethnic differences in fluorosis prevalence.

Of the previous studies on genetic variation and fluorosis risk, the contribution or association of SNPs to dental fluorosis or skeletal fluorosis has been reported in several studies. ${ }^{10} 25$ 30-32 However, none has reported the association between the VDR-FokI polymorphism and skeletal fluorosis of the brick-tea type. Calcium could alleviate the toxic effects of fluoride to a certain extent, ${ }^{33}$ but fluoride ingestion reduces intestinal calcium absorption. Animal studies indicate that excess fluoride has an inhibitory effect on duodenal VDR gene transcription, and thereby hinders the calcium absorption process. ${ }^{34}$ The VDR-FokI gene polymorphism has been reported to be associated with bone metabolism and calcium absorption. ${ }^{21-23}$ Moreover, evidence has indicated that the TT and CT forms of the VDR-FokI polymorphism are associated with decreased VDR efficiency, compared with the TT genotype. ${ }^{24}$ Therefore, in the present study, we focused on the role of the VDR-FokI polymorphism in skeletal fluorosis of the brick-tea type. We found that the $>20 \%$ reduction in the risk of skeletal fluorosis related to the CT/TT genotype in VDR-FokI in all participants was largely attributable to the reduced risk in Mongolian participants. Moreover, this protective effect remained significant after adjustment for age, sex, ITF and UF. These results suggest that the protective of the CT/TT genotype against skeletal fluorosis of the brick-tea type might be present among Mongolian participants.

Factors, including age, sex, dose and duration of fluoride intake, that influence fluoride toxicity and clinical presentation are the major risk factors for fluorosis. ${ }^{4} 8$ Hence we investigated the potential interactions between the VDR-FokI SNP and known risk factors in Mongolian participants. We found that this protective role of the CT/TT genotype of VDR-FokI against brick-tea type fluorosis appeared to be more pronounced in participants with $>3.2 \mathrm{mg} / \mathrm{L} \mathrm{UF},>7.0 \mathrm{mg} /$ day ITF or aged 46-65 years. Therefore, our results suggested that this protective effect was pronounced under high fluoride exposure conditions. However, these findings of the VDR-FokI SNP analysis stratified by risk factors need to be interpreted with caution because the data were sparse when several factors were investigated simultaneously. The amount of fluoride accumulation in the body increased with age ${ }^{35-37}$ so the prevalence and severity of skeletal fluorosis also increased with age. In our data, this protective effect of the CT/TT genotype was limited in Mongolian participants aged 46-65 years. For younger people, the fluoride load in the body was low because of a shorter period of fluoride exposure, and hence the prevalence of fluorosis was small. Thus it is necessary to investigate this interaction in a large sample population. For older people ( $\geq 66$ years), the protective effect of the $\mathrm{CT} / \mathrm{TT}$ genotype might be compromised by the toxicity of a high fluoride load in the body.

There are several potential limitations in this study. First, in the power analysis, we found that our sample size of Tibetan and Han participants was inadequate, and so the true association of the VDR-FokI polymorphism with skeletal fluorosis in these two ethnicities needs further study. Second, a study in Indian girls indicated that after supplementation of calcium, carriers of the TT genotype had a significant increase in bone mass compared with the CC genotype, ${ }^{20}$ which suggested that the VDR-FokI polymorphism may influence bone metabolism through dietary calcium. Unfortunately, we did not have data on dietary calcium. We need to investigate the interaction of the VDR-FokI SNP with dietary calcium in fluorosis. Third, we did not have data on serum vitamin D levels. Fourth, VDR contains numerous SNPs. Apart from FokI, others SNPs, such as BsmI, also play an important role in bone metabolism. It is necessary to study the association between these SNPs and skeletal fluorosis.

\section{CONCLUSIONS}

In summary, the CT/TT genotype of VDR-FokI may play a protective role in brick-tea type fluorosis, and this protective effect was apparent in Mongolian participants. For Mongolian participants, this protective effect was apparent in participants with $>3.2 \mathrm{mg} / \mathrm{L} \mathrm{UF},>7.0 \mathrm{mg} /$ day ITF or aged 46-65 years. Improved understanding of such gene-environment interactions would not only contribute to knowledge on skeletal fluorosis of the brick-tea type but also help in establishing preventive measures. Therefore, larger studies are necessary to study the role of genes and/or polymorphic sites influencing bone mass in the pathogenesis of fluorosis.

\section{Author affiliations \\ ${ }^{1}$ Centre for Endemic Disease Control, Chinese Centre for Disease Control and Prevention, Harbin Medical University, Harbin, Heilongjiang, China \\ ${ }^{2}$ Key Laboratory of Aetiology and Epidemiology, Education Bureau of Heilongjiang Province and Ministry of Health, Harbin, Heilongjiang, China ${ }^{3}$ Chongqing Blood Centre, Chongqing, China}

Acknowledgements The authors thank all of the participates in this study and numerous members of the Centre for Endemic Disease Control of the Chinese Centre for Disease Control and Prevention, the Inner Mongolia Institute for Endemic Disease Control, the Qinghai Institute for Endemic Disease Control and the Sinkiang Institute for Endemic Disease Control.

Contributors YG, YY and DS participated in the design of the study. YG, $Y Y, D Y, Y L, D L$ and $M Q$ participated in the interpretation of the data and statistical analyses. YC, QY, WJ and FC participated in the acquisition of the data. The manuscript was drafted by DY and $Y L$, and was revised by $Y G$ and $Y Y$.

Funding The study was supported by the National Natural Science Foundation of China (No 81172605 and 30800956 ).

Competing interests None declared.

Patient consent Obtained. 
Ethics approval The study was proved by the Harbin Medical University Ethics Committee (HMUIRB20120021).

Provenance and peer review Not commissioned; externally peer reviewed.

Data sharing statement No additional data are available.

Open Access This is an Open Access article distributed in accordance with the Creative Commons Attribution Non Commercial (CC BY-NC 4.0) license, which permits others to distribute, remix, adapt, build upon this work noncommercially, and license their derivative works on different terms, provided the original work is properly cited and the use is non-commercial. See: http:// creativecommons.org/licenses/by-nc/4.0/

\section{REFERENCES}

1. Mandinic Z, Curcic M, Antonijevic B, et al. Relationship between fluoride intake in Serbian children living in two areas with different natural levels of fluorides and occurrence of dental fluorosis. Food Chem Toxicol 2009; 47:1080-4

2. Jha SK, Mishra VK, Sharma DK, et al. Fluoride in the environment and its metabolism in humans. Rev Environ Contam Toxicol 2011:211:121-42

3. Buzalaf MA, Whitford GM. Fluoride metabolism. Monogr Oral Sci 2011;22:20-36.

4. Krishnamachari KA. Skeletal fluorosis in humans: a review of recent progress in the understanding of the disease. Prog Food Nutr Sci 1986;10:279-314

5. Choubisa SL, Choubisa L, Choubisa DK. Endemic fluorosis in Rajasthan. Indian J Environ Health 2001;43:177-89.

6. Malde MK, Zerihun L, Julshamn K, et al. Fluoride intake in children living in a high-fluoride area in Ethiopia-intake through beverages. Int J Paediatr Dent 2003;13:27-34.

7. Jin C, Yan Z, Jian-Wei L, et al. Prevention and control of brick-tea type fluorosis-a 3-year observation in Dangxiong, Tibet. Ecotoxicol Environ Saf 2003;56:222-7.

8. Dhar V, Bhatnagar M. Physiology and toxicity of fluoride. Indian $J$ Dent Res 2009;20:350-5.

9. Richards JB, Rivadeneira F, Inouye M, et al. Bone mineral density, osteoporosis, and osteoporotic fractures: a genome-wide association study. Lancet 2008;371:1505-12.

10. Zhang T, Shan KR, Tu X, et al. Myeloperoxidase activity and its corresponding mRNA expression as well as gene polymorphism in the population living in the coal-burning endemic fluorosis area in Guizhou of China. Biol Trace Elem Res 2013;152:379-86.

11. Kurt O, Yilmaz-Aydogan $\mathrm{H}$, Uyar $\mathrm{M}$, et al. Evaluation of ERalpha and VDR gene polymorphisms in relation to bone mineral density in Turkish postmenopausal women. Mol Biol Rep 2012;39:6723-30.

12. Li C, Li Y, Gao LB, et al. Vitamin D receptor gene polymorphisms and the risk of colorectal cancer in a Chinese population. Dig Dis Sci 2009;54:634-9.

13. Uitterlinden AG, Fang $Y$, Van Meurs JB, et al. Genetics and biology of vitamin D receptor polymorphisms. Gene 2004;338:143-56.

14. Puranik CP, Ryan KA, Yin Z, et al. Fluoride modulates parathyroid hormone secretion in vivo and in vitro. Cells Tissues Organs 2015;200:413-23.

15. Morrison NA, Qi JC, Tokita A, et al. Prediction of bone density from vitamin D receptor alleles. Nature 1994;367:284-7.

16. Morrison NA, Yeoman R, Kelly PJ, et al. Contribution of trans-acting factor alleles to normal physiological variability: vitamin $D$ receptor gene polymorphism and circulating osteocalcin. Proc Natl Acad Sci USA 1992;89:6665-9.

17. Arabi A, Zahed L, Mahfoud Z, et al. Vitamin D receptor gene polymorphisms modulate the skeletal response to vitamin $D$ supplementation in healthy girls. Bone 2009;45:1091-7.

18. Barr $\mathrm{R}$, Macdonald $\mathrm{H}$, Stewart $\mathrm{A}$, et al. Association between vitamin $\mathrm{D}$ receptor gene polymorphisms, falls, balance and muscle power: results from two independent studies (APOSS and OPUS). Osteoporos Int 2010;21:457-66.

19. Christensen MH, Apalset EM, Nordbo Y, et al. 1,25-dihydroxyvitamin $D$ and the vitamin $D$ receptor gene polymorphism Apa1 influence bone mineral density in primary hyperparathyroidism. PLOS ONE 2013;8:e56019.

20. Sanwalka N, Khadilkar A, Chiplonkar S, et al. Influence of vitamin D receptor gene Fok1 polymorphism on bone mass accrual post calcium and vitamin D supplementation. Indian J Pediatr 2015;82:985-90.

21. Ames SK, Ellis KJ, Gunn SK, et al. Vitamin D receptor gene Fok1 polymorphism predicts calcium absorption and bone mineral density in children. J Bone Miner Res 1999;14:740-6.

22. Abrams SA, Griffin IJ, Hawthorne KM, et al. Vitamin D receptor Fok1 polymorphisms affect calcium absorption, kinetics, and bone mineralization rates during puberty. $J$ Bone Miner Res 2005;20:945-53.

23. Terpstra L, Knol DL, Van Coeverden SC, et al. Bone metabolism markers predict increase in bone mass, height and sitting height during puberty depending on the VDR Fok1 genotype. Clin Endocrinol (Oxf) 2006;64:625-31.

24. Laaksonen MM, Kärkkäinen MU, Outila TA, et al. Vitamin D receptor gene start codon polymorphism (Fokl) is associated with forearm bone mineral density and calcaneal ultrasound in Finnish adolescent boys but not in girls. $J$ Bone Miner Metab 2004;22:479-85

25. Wu J, Wang W, Liu Y, et al. Modifying role of GSTP1 polymorphism on the association between tea fluoride exposure and the brick-tea type fluorosis. PLOS ONE 2015;10:e0128280.

26. Grobler SR, Louw AJ, Chikte UM, et al. The relationships between two different drinking water fluoride levels, dental fluorosis and bone mineral density of children. Open Dent $J$ 2009;3:48-54.

27. Kobayashi CA, Leite AL, Peres-Buzalaf $\mathrm{C}$, et al. Bone response to fluoride exposure is influenced by genetics. PLOS ONE 2014;9: e114343.

28. Mousny M, Banse $\mathrm{X}$, Wise $\mathrm{L}$, et al. The genetic influence on bone susceptibility to fluoride. Bone 2006;39:1283-9.

29. Mousny M, Omelon S, Wise L, et al. Fluoride effects on bone formation and mineralization are influenced by genetics. Bone 2008;43:1067-74

30. Huang $\mathrm{H}, \mathrm{Ba} Y$, Cui $\mathrm{L}$, et al. $\mathrm{COL} 1 \mathrm{~A} 2$ gene polymorphisms (Pvu II and Rsa I), serum calciotropic hormone levels, and dental fluorosis. Community Dent Oral Epidemiol 2008;36: 517-22.

31. Ba $\mathrm{Y}$, Zhang $\mathrm{H}$, Wang $\mathrm{G}$, et al. Association of dental fluorosis with polymorphisms of estrogen receptor gene in Chinese children. Biol Trace Elem Res 2011:143:87-96.

32. Everett ET, Yan D, Weaver M, et al. Detection of dental fluorosis-associated quantitative trait loci on mouse chromosomes 2 and 11. Cells Tissues Organs 2009;189:212-18.

33. Teotia M, Teotia SP, Singh KP. Endemic chronic fluoride toxicity and dietary calcium deficiency interaction syndromes of metabolic bone disease and deformities in India: year 2000. Indian J Pediatr 1998;65:371-81.

34. Tiwari S, Gupta SK, Kumar K, et al. Simultaneous exposure of excess fluoride and calcium deficiency alters VDR, CaR, and calbindin D $9 \mathrm{k}$ mRNA levels in rat duodenal mucosa. Calcif Tissue Int 2004;75:313-20.

35. Weidmann SM, Weatherell JA, Whitehead RG. The effect of fluorine on the chemical composition and calcification of bone. J Pathol Bacteriol 1959;78:435-45.

36. Parkins FM, Tinanoff N, Moutinho M, et al. Relationships of human plasma fluoride and bone fluoride to age. Calcif Tissue Res 1974; 16:335-8.

37. Richards A, Mosekilde L, Søgaard CH. Normal age-related changes in fluoride content of vertebral trabecular bone-relation to bone quality. Bone 1994;15:21-6. 